\title{
Five years of citizen science and standardised field surveys in an informal urban green space reveal a threatened Eden for wild bees in Brussels, Belgium
}

\author{
NICOLAS J. VEREECKEN, ${ }^{1}$ TIMOTHY WEEKERS,${ }^{1}$ LEON MARSHALL, 1 \\ JENS D'HAESELEER, ${ }^{2}$ MAARTEN CUYPERS, ${ }^{2}$ ALAIN PAULY, ${ }^{3}$ \\ BERNARD PASAU, ${ }^{4}$ NICOLAS LECLERCQ, ${ }^{1}$ ALAIN TSHIBUNGU, ${ }^{1}$ \\ JEAN-MARC MOLENBERG ${ }^{1}$ and STÉPHANE DE GREEF ${ }^{1}{ }^{1}$ Agroecology Lab, Université Libre \\ de Bruxelles, Brussels, Belgium, ${ }^{2}$ Natuurpunt Studie, Mechelen, Belgium, ${ }^{3}$ Directorate Taxonomy \& Phylogeny, Royal Belgian \\ Institute of Natural Sciences, Brussels, Belgium and ${ }^{4}$ Natagora Bruxelles, Mundo-B, Bruxelles, Belgium
}

\begin{abstract}
Urbanisation is often put forward as an important driver of biodiversity loss, including for pollinators such as wild bees. However, recent evidence shows that the mosaics of urban green spaces, and in particular certain categories of informal urban green spaces (IGS), can play an important role to help native wild bees thrive in cities.

2. Here, we describe the results of 5 years of citizen science and standardised field surveys of wild bees conducted at the Friche Josaphat, a 24-ha urban wasteland in the Brussels-Capital Region (Belgium). These field surveys were initiated following the planned restructuring and partial destruction of this site by the regional authorities.

3. We recorded a total of 2507 specimens belonging to 127 species of wild bees, i.e. $60.5 \%$ of the 210 species recorded regionally, including nine that are threatened with extinction at national or European scales. The Friche Josaphat encompasses a significant share of the functional and phylogenetic diversity of wild bees known from the Brussels-Capital Region and is one of the most species-rich localities known to date for wild bees in Belgium.

4. Collectively, our results highlight the strong complementarity of citizen science and academic approaches in biodiversity surveys, and they reaffirm that wastelands are essential components of urban biodiversity. Our study stresses the need to provide biodiverse IGS with a formal status within the mosaic of urban green spaces but also to acknowledge and safeguard their natural capital and the multiple ecosystem services they provide.
\end{abstract}

Key words. Biodiversity, brownfields, pollinators, urban green spaces, urban planning, vacant lands, wastelands, wild bees.

\begin{abstract}
Introduction
Urbanisation as a spatial process is a priori expected to have deleterious impacts on biodiversity, through its contribution to habitat fragmentation and the irreversible conversion of green spaces into impervious surfaces (e.g., McDonald et al., 2008; Vimal et al., 2012). Yet, parallel evidence suggests that some groups of organisms might actually thrive in cities (Miller \& Hobbs, 2002; Araujo, 2003; Kühn \& Klotz, 2006). By and large,
\end{abstract}

Correspondence: Nicolas J. Vereecken, Agroecology Lab, Université libre de Bruxelles (ULB), Avenue F.D. Roosevelt 50, B-1050 Bruxelles, Belgium. E-mail: nicolas.vereecken@ulb.be our cities and megapolises are still home to relatively high numbers of native and sometimes rare or threatened species (e.g. Aronson et al., 2014), and also many exotic taxa (Fitch et al., 2019; de Souza e Silva et al., 2020; Taggar et al., 2021). The urban wildlife is the key to ecosystem function and resilience in cities under global change scenarios, but it also actively supports the mental health, physical well-being and social interactions of present-day populations of urban dwellers (Barton \& Grant, 2013; Bratman et al., 2019). Indeed, the benefits of regular access to (large) urban green spaces (UGS) were particularly exacerbated across the world urban centres during the recent COVID-19 pandemic and its associated travel restrictions (Pfefferbaum \& North, 2020; Xie et al., 2020; Ahmadpoor \& 
Shahab, 2021). For all these reasons, urban areas have become increasingly recognised as important targets for wildlife conservation (Goddard et al., 2010; Dearborn \& Kark, 2010; Kowarik, 2011; Shwartz et al., 2014), as well as to comply with the UN sustainable development goals aiming 'to make cities and human settlements inclusive, safe, resilient, and sustainable' (United Nations, 2015; Apfelbeck et al., 2020).

The added value of cities for biodiversity conservation lies in their mosaics of typologically diverse urban green spaces (UGS), from playing fields to highly manicured environments such as managed forests, parks or cemeteries, to semi-natural landscapes, including urban nature reserves (Lepczyk et al., 2017). However, besides these formally acknowledged and managed UGS, a multitude of the so-called informal urban green spaces (IGS) such as 'vacant' lots, street or railway sidings, utility easements, corridors between buildings and riverbanks are typically deprioritised and often represent an underrated piece of the urban nature in the urban planning puzzle (Rupprecht \& Byrne, 2014). Among these neglected IGS, urban wastelands (or 'brownfield' lands) come in all sizes and shapes and unlike the coherently managed urban parks, they often meet the diverse 'nature needs' of their users who, contrary to urban planners, do not view IGS as being 'vacant' or as an 'empty space' that should be developed (Rupprecht et al., 2015; Botzat et al., 2016). In their meta-analysis spanning across 37 independent studies, Bonthoux et al. (2014) show that wastelands are indeed an essential component of urban biodiversity, particularly for birds (see also Villaseñor et al., 2020) and plants (e.g., Zorenko 2003; Godefroid et al., 2007; Schadek et al., 2008; Vakhlamova et al., 2014), but also for beetles (Coleoptera) (Small et al., 2002; Small et al., 2002). To date, the explicit contribution of wastelands to the diversity of other groups of organisms relevant to urban ecosystem services provision, such as wild bees (Hymenoptera, Apoidea), remains relatively poorly understood (but see Fischer et al., 2016; Twerd \& Banaszak-Cibicka, 2019).

In this study, we assess the contribution of the Friche Josaphat, the largest urban wasteland in Brussels, to the diversity of wild bees at the scale of the Brussels-Capital Region. We compiled 5 years of field surveys to characterise the fauna of this site, and we compare it to the recently updated regional checklist of wild bees. Specifically, we used different metrics to characterise the multi-faceted biodiversity of wild bees at our target site compared to the regional scale, and we also used null models of community assembly to test whether the wild bee species assemblage recorded at our study site encompasses species that are significantly less or more similar (considering their behavioural traits and evolutionary history) than in random communities consisting in the same number of species recorded at the regional scale. Our approach will help determine the relevance and originality of the Friche Josaphat biodiversity at the regional scale, as well as characterising the potential role of environmental filtering in the wild bee community assembly process if the Friche Josaphat is home to species that are more similar (considering their behavioural traits and evolutionary history) than in random communities. The importance of informal urban green spaces will be discussed in light of our results to address their under-reported role in the conservation of urban bees and urban biodiversity.

\section{Materials and methods}

Study site

The 24-ha Friche Josaphat (Fig. 1) is currently one of the few remaining wastelands in the Brussels-Capital Region (Belgium; $\mathrm{N} 50.863224, \mathrm{E} 4.395417)$ and by far the largest in size. This site is a former railway marshalling yard extending across the Schaerbeek and Evere municipalities; in other words, it is a post-industrial urban fallow now turned into a semi-natural meadow, and one of the largest unfragmented green spaces entirely enclaved in the dense urban matrix of Brussels (Fig. 1). After the closure of the Schaerbeek-Josaphat marshalling yard along the Railway Line 26 (Mechelen-Etterbeek-Hal) in 1994, the railway infrastructure was dismantled and the site was subsequently cleaned up, levelled with soil and sand, and turned into a semi-natural grassland in 2013 (Fig. 1).

The site is currently owned by the Urban Development Corporation of the Brussels-Capital Region (Société d'Aménagement Urbain, SAU) and according to present-day development plans, the semi-natural meadow will be largely destroyed and turned into impervious surfaces, perhaps at the exception of seven hectares converted into biodiversity-focused embankment (3.0 ha), an active linear park (2.8 ha) and a relaxation space (1.1 ha). This public announcement has stimulated collaborative research among citizens, researchers and local non-profit organisations to document the wildlife conservation value of the Friche Josaphat for a variety of taxonomic groups (see also SaintenoySimon 1984, 2003, 2012, 2018, 2019; Kekenbosch 2010; Devillers et al., 2019), with the overarching goal to propose alternative, biodiversity-inclusive and participatory management approaches for the Friche Josaphat site. Our contribution to this collective endeavour was to conduct new field surveys and collect all available and verified records relevant to the wild bees of the Brussels-Capital Region.

\section{Data collection}

Our dataset encompasses occurrence records of wild bees obtained over 245 days in the field between 10 June 2015 and 31 October 2020, through opportunistic observations as well as through parallel and independent, standardised, targeted biological surveys using a combination of pan traps and insect netting (variable transect walks with fixed search time) (Westphal et al., 2008; Normandin et al., 2017). The methodology on the use of pan traps for bee surveys is detailed in the study by Vereecken et al. (2021) and in the Supplementary Information.

Opportunistic surveys at the Friche Josaphat by amateur naturalists started in 2015 up to the present day; we compiled all validated observations available through the citizen science platforms Observations.be/Waarnemingen.be (2021), including the date, time, geographic coordinates, field notes, as well as photographs as supporting evidence. Individual records obtained through citizen science surveys relate to a single species, yet they can include the number of specimens of the species observed locally which can amount to several hundreds in the case of a nesting aggregation. 


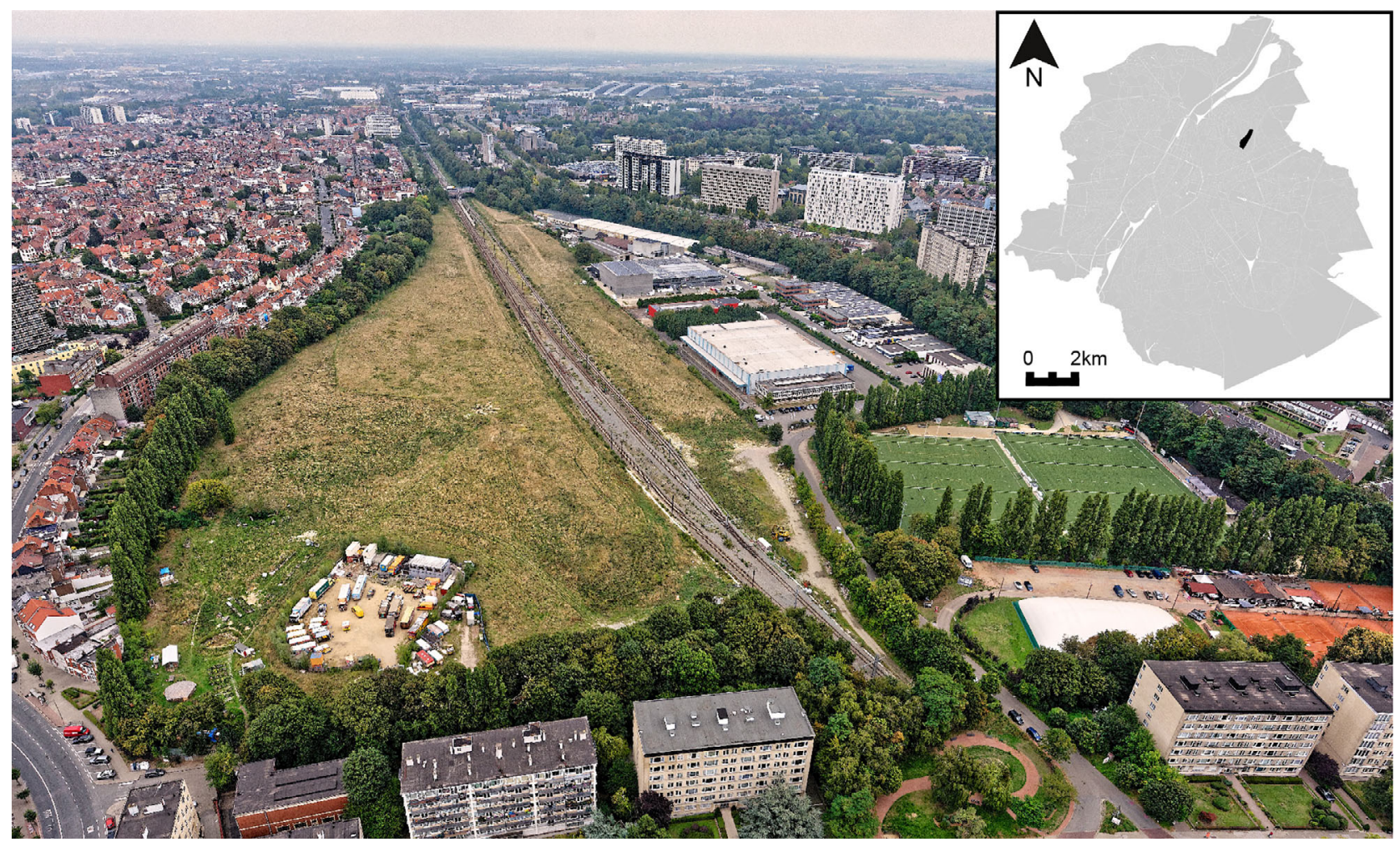

Figure 1. Aerial view of the Friche Josaphat wasteland in Brussels (Belgium) surrounded by a row of tall trees and the railway tracks (Photo ${ }^{\odot} \mathrm{S}$. Schmitt/ Global View - Photographie aérienne), and its location in the Brussels-Capital Region (in the top right corner). [Color figure can be viewed at wileyonlinelibrary.com]

Standardised field surveys consisted in combining insect netting and pan traps (Westphal et al., 2008). All bees were then pinned and labelled, then identified down to the species level using the key to the bee genera of Europe (Michez et al., 2019), and the available key to the Belgian Halictidae (Pauly 2019). We used the most recent update of the bee checklist of the bees of Belgium (Drossart et al., 2019) along with the following keys: Amiet (1996) for Bombus spp. (Apidae), Amiet (1999) for Colletes and Hylaeus spp. (Colletidae), Amiet et al. (2004) for Anthidium, Chelostoma, Coelioxys, Megachile, Osmia and Stelis spp. (Megachilidae), Amiet et al. (2007) for Anthophora, Ceratina, Epeolus, Eucera and Nomada spp. (all Apidae) and Dasypoda, Macropis and Melitta spp. (all Melittidae), Schmid-Egger and Scheuchl (1997) and Amiet et al. (2010) for Andrena and Panurgus spp. (Andrenidae). Identifications were cross checked with the UK field and identification guides of Falk (2015) and Else and Edwards (2018). Individual records associated with standardised field surveys correspond to pinned specimens curated at the entomological collection of the Agroecology Lab (Université libre de Bruxelles, Belgium).

\section{Statistical analyses}

We first prepared a species accumulation curve using all available records by randomly assigning the order of specimens observed (Gotellli \& Colwell, 2001) and the specaccum function in the 'vegan' package (Oksanen et al., 2020) to visually assess the adequacy of our wild bee field surveys. This and all following analyses were conducted in RStudio (2020) for R (R Core Team, 2020). We then calculated the total expected species richness (or the number of unobserved species) using a bootstrapping procedure with $n=999$ random reorganisations of sampling order. Total expected species richness was assessed using Chao (1984), Jack1 (First order jackknife), and Jack2 (Second order jackknife) estimators with the alpha.estimate function in the "BAT" package (version 2.5.0.) (Cardoso et al., 2015) (see Normandin et al., 2017 for details).

For functional community structure approaches, we used the methodology described in the study by Vereecken et al. (2021): the taxonomic classification and functional traits of wild bee species in the Brussels-Capital Region used in this study are available in the Supporting Information Table S1. The mixed matrix of qualitative and quantitative functional traits (between the columns 'ITD' and 'Diet.breadth') was converted into a Gower distance matrix with the gowdis function in the 'FD' package (version 1.0-12) (Laliberté \& Legendre 2010; Laliberté et al., 2014). We then used the pcoa function from the "ape" package (version 5.0) (Paradis \& Schliep, 2019) to perform a principal coordinates analysis (PCoA) based on the Gower distance matrix above, and we used the first two principal coordinates to plot the functional space of the Friche Josaphat

(C) 2021 Royal Entomological Society., Insect Conservation and Diversity, doi: 10.1111/icad.12514 
and the Brussels-Capital Region wild bee communities as convex hulls, following the framework described by Mouillot et al. (2013). We excluded species in the subgenus Micrandrena (Andrena, Andrenidae) from the analyses as they are notoriously challenging to identify and still await a proper revision. We also excluded Hylaeus paulus (Colletidae) (one specimen collected at the Friche Josaphat) and Nomada pleurosticta (Apidae) (one specimen collected in Brussels outside the Friche Josaphat) because we failed to compute their inter-tegular distance (ITD). We used the multidimFD function by Mouillot et al. (2013) to characterise the nestedness component of the functional $\beta$-diversity between the wild bee community of the Friche Josaphat and that of the Brussels-Capital Region. This was performed by computing the proportion of the nested, multidimensional convex hull of the Friche Josaphat (FRic, in \%, as functional richness or the proportion of functional space filled by species present in the assemblage).

To compare the phylogenetic structure of the Friche Josaphat community to that of the Brussels-Capital Region, we adopted the approach described in the study by Vereecken et al. (2021) by building a polytomous, ultrametric tree based on the Linnaean taxonomic hierarchy of wild bees, and we used the 'ggtree' package (version 3.12) (Yu et al., 2017; Yu, 2020) to visualise the resulting phylogenetic tree with its associated location data. We used this 'Linnaean' approach as a proxy to the phylogeny following Vereecken et al. (2021) who showed that the results obtained for phylogenetic diversity metrics were largely consistent between a 'Linnaean' approach and the use of a multi-gene molecular phylogeny.

Last, for both the trait-based functional and phylogenetic approaches, we have computed the mean functional and phylogenetic distances (MFD/MPD), an average for the pairwise (functional or phylogenetic) distances values across all pairs of taxa in a community (in the functional space or across the phylogeny). We also computed a trait-based functional and phylogenetic mean nearest taxon distance (MNTD), a metric that provides an average of the (functional or phylogenetic) distances between each species and its nearest (functional or phylogenetic) neighbour in the community (Webb et al., 2002; see also Dorchin et al., 2018). Specifically, we computed the standardised effect sizes (SES; Gotelli \& Cabe, 2002) by shuffling taxa labels $(n=999)$ across tips of the functional traits dendrogram (for MFD) and the taxonomy-based phylogeny (for MPD) across all taxa included in the regional bee fauna to compare the functional and phylogenetic scores for MFD/MPD. For MNTD, we used the same procedure with the pairwise cophenetic distances of the taxonomy-based phylogeny. These variables were calculated with the 'picante' package (Kembel et al., 2010).

\section{Results and discussion}

\section{The wild bee fauna of the Friche Josaphat in Brussels}

Our dataset for the Friche Josaphat comprises 2507 individual records, representing 7188 specimens and 127 species of wild bees, as well as the honey bee (Apis mellifera) (Supporting Information Table S1). The citizen science approach yielded
6038 individual records and 105 species over 239 days of observations, whereas the standardised field surveys yielded 1150 individual records and 95 species over 17 days of observations. The highest estimation of species richness for the Friche Josaphat was associated with the second order Jackknife estimator (168.84 species), while the lowest was the first-order Jackknife estimator (150 species). The Chao estimator indicated the probable presence of 153.67 species at our study site. Collectively, these results, along with the shape of the species accumulation curve reaching a plateau (Fig. 2), indicate that we have observed $75.81-85.33 \%$ of the estimated species richness at the Friche Josaphat. In terms of taxonomic diversity, the wild bees recorded at the Friche Josaphat belong to six families and 26 genera (Fig. 2), and they account for $60.6 \%$ of the 210 species recorded in the Brussels-Capital Region between February 1999 and March 2020, or $34.5 \%$ of the 345 species assessed recently in the Belgian Red List of Bees (Drossart et al., 2019).

The 12 most common species are illustrated and listed in the Supporting Information Figure S1 along with their abundance in the dataset; they represented $74.9 \%$ of all samples recorded. Our records encompass seven wild bee species of conservation concern at the scale of Belgium: these include the nationally 'Vulnerable' species Eucera longicornis (Apidae) and the 'Near threatened' species Andrena bimaculata (Andrenidae), Bombus hortorum (Apidae), Coelioxys rufescens (Megachilidae), Osmia aurulenta (Megachilidae), Osmia spinulosa (Megachilidae) and Stelis phaeoptera (Megachilidae) (Drossart et al., 2019). The Friche Josaphat is also home to species threatened with extinction at the European scale, such as the 'Vulnerable' Colletes fodiens (Colletidae) and the 'Near threatened' Lasioglossum sexnotatum (Halictidae) (Nieto et al., 2014) (Table S1). We also noted the presence of four species recorded in the BrusselsCapital Region that are only known from the Friche Josaphat so far, namely Hylaeus paulus (Colletidae), Anthidium punctatum (Megachilidae) and Osmia aurulenta (Megachilidae); the record of Anthidium septemspinosum (Megachilidae) through citizen sciences surveys was not only unique to the Friche Josaphat, but also a new addition to the Belgian checklist of wild bees (Vereecken et al., unpublished).

A total of 72 bee species were recorded both through citizen sciences and standardised field surveys at the Friche Josaphat. The citizen sciences records included another 33 additional wild bee species not detected through standardised field surveys, whereas the standardised field surveys helped adding 23 species not detected through the citizen science surveys (Fig. 2).

We hypothesize that the high biodiversity of wild bees highlighted at the Friche Josaphat stems from several important factors, including (i) the lack of formal management of the Friche Josaphat except the creation of temporary ponds since 2013; (ii) the strong complementarity of citizen science and standardised methods in biodiversity surveys, particularly when they aim at maximising the number of species recorded in a check-list format; and (iii) the proximity of the railway and railway edges to the Friche Josaphat (Fig. 1). Indeed, linear transport infrastructures such as railways, but also highways, waterways and power transmission lines are increasingly acknowledged as important biodiversity corridors for invertebrates, including for pollinators and wild bees in particular (e.g., Wojcik \& 
(a)

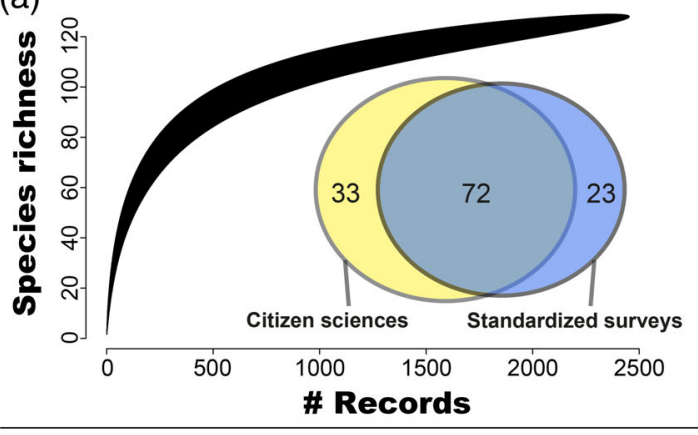

(b)

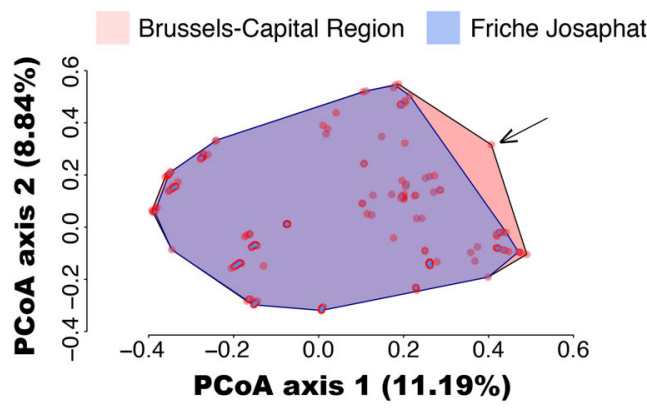

(c)

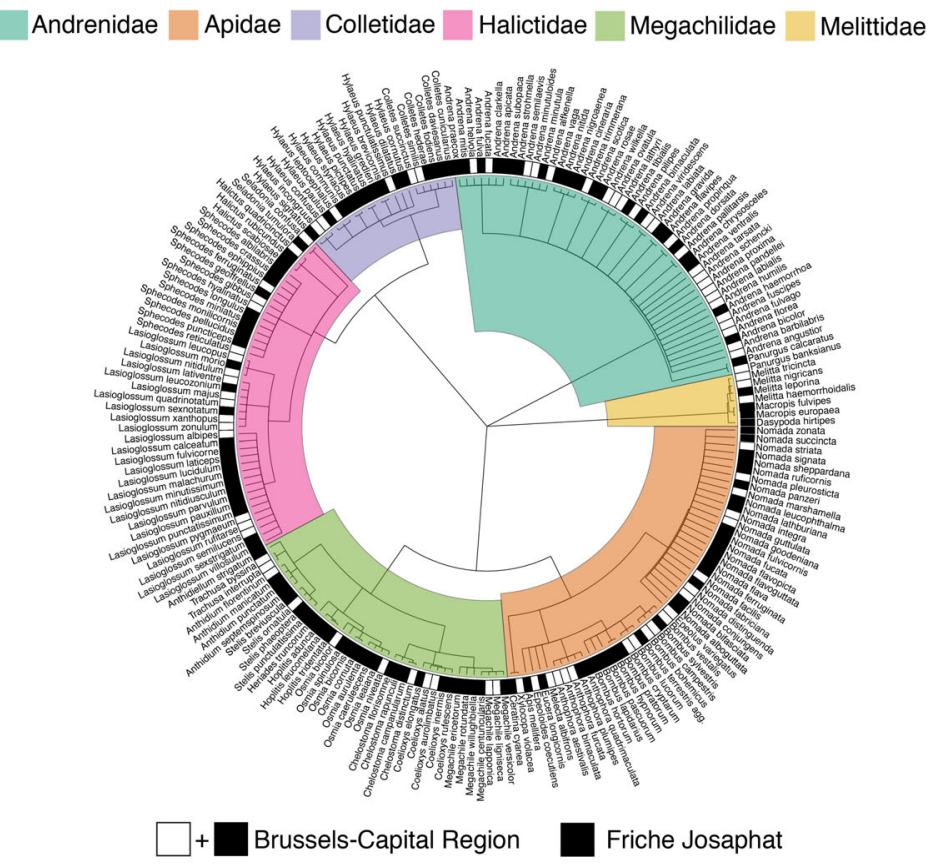

Figure 2. Analysis of the wild bee community structure associated with the Friche Josaphat and the Brussels-Capital Region. (a) Species accumulation curve using a bootstrapping procedure with $\mathrm{n}=999$ random reorganisations of sampling order. The mean species accumulation curve of the Friche Josaphat reaches a plateau, and estimators indicate that we have observed $75.81-85.33 \%$ of the estimated local species richness, which confirms the adequacy of our field surveys. The Venn diagram indicates the number of unique and shared species recorded by citizen science and standardised surveys. (B) The pink convex hull represents $100 \%$ of the multi-dimensional functional space occupied by all species recorded in the Brussels-Capital Region, and the blue convex hull represents $92.21 \%$ of the multi-dimensional functional space occupied by species from the Friche Josaphat. Pink and blue circles are species of wild bees associated with each community; the arrow indicates the position of Coelioxys aurolimbata (Hym. Megachilidae), a uniquely large cuckoo bee species associated with a host (Megachile ericetorum (Hym. Megachilidae) displaying strong preference (i.e., oligolecty) for host plants in the family Fabaceae (sensu Dötterl \& Vereecken 2010; Rasmussen et al., 2020). All other Coelioxys species found in the Brussels-Capital Region or in the Friche Josaphat are associated with pollen generalist (i.e., polylectic) hosts. (c) Phylogenetic classification of wild bees belonging to the six families recorded in the Brussels-Capital Region (black and white squares) and in the Friche Josaphat (black squares only). [Color figure can be viewed at wileyonlinelibrary.com]

Buchmann, 2012; Wagner et al., 2014; Hill \& Bartomeus, 2016; Steinert et al., 2020).

Our results on the trait-based functional community structure illustrate that the Friche Josaphat represents $92.21 \%$ of the functional space occupied by all wild bee species recorded in the Brussels-Capital Region (Fig. 2; Supporting Information Figure S2). Our analysis of the community structure of bees indicates that, compared to the Brussels-Capital Region, the diversity of the Friche Josaphat community is significantly reduced taxonomically (211 vs. 128 species), functionally (FD observed $=19.847$ vs. $14.304 ; P$-value $=0.03)$ and phylogenetically $(\mathrm{PD}$ observed $=10.365$ vs. $8.759 ; P$-value $=0.0280)$ (see also Fig. 2). However, we found no significant difference between the Brussels-Capital Region and the Friche Josaphat communities when we computed the MFD/MPD (MFD zscore $=-0.027$ and $P$-value $=0.461 ;$ MPD z-score $=-1.536$ and $P$-value $=0.077)$, or the trait-based functional and phylogenetic mean nearest taxon distance (MNTD) $\left(\mathrm{MNTD}_{\text {traits }} \mathrm{z}\right.$ score $=-1.130$ and $P$-value $=0.124 ;$ MNTD $_{\text {phylo }} \mathrm{Z}$ - score $=-1.228$ and $P$-value $=0.115$ ). These results illustrate that the Friche Josaphat encompasses a randomly nested subset of the wild bee fauna of the Brussels-Capital Region from a functional and phylogenetic perspective and also suggest a negligible role of environmental filtering towards certain combinations of traits or taxonomic groups in the community assembly process. As such, the Friche Josaphat is therefore currently the richest semi-natural site at the regional level, and the fact that its functional and phylogenetic structure is not significantly different from random communities makes it an ideal site to 'showcase' the diversity of urban bees in Brussels.

To date, the most biodiverse site in the Brussels-Capital Region for wild bees was the flower-rich, 5.3 ha 'Jean Massart' botanical garden, a Natura 2000 site at Auderghem, which is home to 112 species (Pauly, 2019; surveyed between 1975 and 2016). Other formally recognised UGS relevant for wild bee diversity include several nature reserves such as the Vogelzangbeek (Anderlecht, 20 ha, 51 spp.), the Scheutbos (Molenbeek, 66 ha, 80 spp.) or the Moeraske (Evere, 14 ha, 69 spp.) 
according to the citizen science online platforms Observations. be/Waarnemingen.be. The Friche Josaphat also turns out to be one of Belgium's most diverse sites for wild bees, since the only other known 'hotspots' at the scale of Belgium include sites with comparable species counts, but that are much larger nature reserves and/or sites that have been surveyed for several decades (e.g. the Belvédère and Fond-Saint-Martin nature reserve at Hansur-Lesse with 131 spp. surveyed between 1951 and 2017; Pauly, 2019; or the 500+ ha nature reserves Most (a peaty depression) and Keiheuvel (a land dune area) at Balen, with 136 spp. surveyed between 2012 and 2017 (Lambrechts et al., 2015; Jacobs et al., 2019).

The future of urban wastelands and other informal urban green spaces

Collectively, our results have allowed us to confirm recent findings by Twerd and Banaszak-Cibicka (2019) that urban wastelands represent a hitherto underrated and largely overlooked category of UGS with a high potential for the conservation of wild bees in metropolises. More coordination is required among stakeholders to identify the local factors contributing to the high biodiversity of wild bees at the Friche Josaphat: for example, Strauss \& Biedermann (2006) have provided evidence that phytophagous insects in biodiverse urban brownfields have clear preferences for certain successional stages of the vegetation. The conservation of a rich local species pool within a city therefore requires coordinated and evidence-based management of the vegetation, and perhaps the maintenance of a mosaic of (all) successional vegetation stages that provide the key host plants of ecologically specialised and generalised species alike. In the case of the Friche Josaphat, addressing these challenges requires an integrated landscape approach tailored to the ecological requirements of the targeted species (see Table S1) (Wilson \& Jamieson, 2019) within the ecological network of important UGS (Ayers \& Rehan, 2021) such as the neighbouring cemetery of Brussels and the Josaphat Park. Another category of IGS or 'vacant land' that received increasing attention over the past decade are urban agriculture plots such as community gardens. Results from recent studies indicate that they too have the potential to harbour particularly high levels of species richness for wild bees and other components of wildlife in urban centres (Normandin et al., 2017; Turo et al., 2021; Vereecken et al., 2021).

'Formal' or 'conventional' UGS such as parks are (increasingly) expensive to maintain, and they often fail to satisfy the urban dwellers' diverse needs. In a context of ever-increasing urbanisation pressure, where spatial (conservation) prioritisation using appropriately chosen objectives is a pressing priority, biodiverse and highly multi-functional IGS should therefore be urgently provided with a formal status within the mosaic of UGS. Indeed, their uncertain legal, socio-economic, and ecological status represent major obstacles in realising these IGS' full societal and environmental potential (e.g., Rupprecht \& Byrne, 2014) and severely limit our capacity to develop wildlife-inclusive urban designs (Apfelbeck et al., 2020). Envisioning participatory management approaches of IGS for urban environmental planning and recreation is of pivotal importance if we are to safeguard their natural capital and the multiple ecosystem services they provide, including for the physical and mental well-being of urban citizens.

\section{Acknowledgements}

The authors are grateful to T. Gaudaire, T. Titeux, D. Burhin, H. Simon, W. Vertommen, W. Proesmans and to all volunteer naturalists for their dedicated contribution to data collection in the field, to L. Motquin and B. De Boeck for their support, to P. Vanormelingen for his comments on the manuscript, and to the Société d'Aménagement Urbain (SAU) for allowing access to the Friche Josaphat during our biodiversity surveys. This study was made possible with financial support from Bruxelles Environnement (BE/IBGE) in the framework of the 'Atlas of the Wild Bees of Brussels' (WildBnB.brussels 2019-2021), as well as from the FNRS/FWO joint programme 'EOS - Excellence Of Science' for the project 'CliPS: Climate change and its impact on Pollination Services (project 30947854)' to N.J.V., T.W., N.L. and L.M.

\section{Author Contributions}

N.J.V. supervised the standardized field surveys, led the writing of the manuscript as well as the statistical analyses; all authors contributed to the collection, analyses and interpretation of data, and reviewed, edited and approved the final version of the manuscript prior to submission.

\section{DATA AVAILABILITY STATEMENT}

The data that support the findings of this study are available from the corresponding author upon reasonable request.

\section{Supporting information}

Additional supporting information may be found online in the Supporting Information section at the end of the article.

Appendix S1: Supporting Information

Supplementary Table 1. The file "SI Table 1.xlsx" contains a list of behavioural and ecological traits of wild bee species, along with their Linnaean classification, covering the fauna of the Brussels-Capital Region and specifying (in the column "Pres. Friche") if, in the framework of this study, the species were recorded only from the Friche Josaphat, or from the BrusselsCapital Region. The dataset also includes a column listing the IUCN status of each species according to the IUCN Red List of bees for Europe (in the column "EU.IUCN.Status", following Nieto et al. 2014) and for Belgium (in the column "BE.IUCN. Status", following Drossart et al. 2019). All other traits used are described in Vereecken et al. (2021). The inter-tegular distance (ITD) of Hylaeus paulus (Colletidae) and Nomada 
pleurosticta (Apidae) were unavailable at the time of the study, and they are therefore marked as "NA" in the dataset.

Supplementary Table 2: Supporting Information

\section{References}

Ahmadpoor, N. \& Shahab, S. (2021) Urban form: realising the value of green space: a planners' perspective on the COVID-19 pandemic. Town Planning Review, 92, 49-55.

Amiet, F. (1996) Apidae 1 (Apis, Bombus, Psithyrus). Insecta Helvetica Fauna 12. CSCF, Neuchâtel, Suisse.

Amiet, F. (1999) Apidae 2. Colletes, Dufourea, Hylaeus, Nomia, Nomioides, Rhophitoides, Rophites, Sphecodes, Systropha. Fauna Helvetica 4. Centre Suisse de cartographie de la faune, Neuchâtel, Suisse.

Amiet, F., Herrmann, M., Müller, A. \& Neumeyer, R. (2004) Apidae 4: Anthidium, Chelostoma, Coelioxys, Dioxys, Heriades, Lithurgus, Megachile, Osmia, Stelis. Fauna Helvetica 9. CSCF/SEG, Neuchâtel, Suisse.

Amiet, F., Herrmann, M., Müller, A. \& Neumeyer, R. (2007) Apidae 5: Ammobates, Ammobatoides, Anthophora, Biastes, Ceratina, Dasypoda, Epeoloides, Epeolus, Eucera, Macropis, Melecta, Melitta, Nomada, Pasites, Tetralonia, Thyreus, Xylocopa. Fauna Helvetica 20. CSCF/SEG, Neuchâtel, Suisse.

Amiet, F., Herrmann, M., Müller, A. \& Neumeyer, R. (2010) Apidae 6: Andrena, Melitturga, Panurginus, Panurgus. Fauna Helvetica 26. CSCF \& SEG, Neuchatel, Suisse.

Apfelbeck, B., Snep, R.P.H., Hauck, T.E., Ferguson, J., Holy, M., Jakoby, C., MacIvor, J.S., Schär, L., Taylor, M. \& Weisser, W.W. (2020) Designing wildlife-inclusive cities that support human-animal co-existence. Landscape and Urban Planning, 200, 103817.

Araújo, M.B. (2003) The coincidence of people and biodiversity in Europe. Global Ecology and Biogeography, 12, 5-12.

Aronson, M.F.J., La Sorte, F.A., Nilon, C.H., Katti, M., Goddard, M.A., Lepczyk, C.A., Warren, P.S., Williams, N.S.G., Cilliers, S., Clarkson, B., Dobbs, C., Dolan, R., Hedblom, M., Klotz, S., Kooijmans, J.L., Kühn, I., MacGregor-For, I., McDonnell, M., Mörtberg, U., Pysek, P., Siebert, S., Sushinsky, J., Werner, P. \& Winter, M. (2014) A global analysis of the impacts of urbanization on bird and plant diversity reveals key anthropogenic drivers. Proceedings of the Royal Society B: Biological Sciences, 281(1780), 20133330

Ayers, A.C. \& Rehan, S.M. (2021) Supporting bees in cities: how bees are influenced by local and landscape features. Insects, 12, 128.

Barton, H. \& Grant, M. (2013) Urban planning for healthy cities. Journal of Urban Health, 90, 129-141.

Bonthoux, S., Brun, M., Di Pietro, F., Greulich, S. \& Bouché-Pillon, S. (2014) How can wastelands promote biodiversity in cities? A review. Landscape and Urban Planning, 132, 79-88.

Botzat, A., Fischer, L.K. \& Kowarik, I. (2016) Unexploited opportunities in understanding liveable and biodiverse cities. A review on urban biodiversity perception and valuation. Global Environmental Change, 39, 220-233.

Bratman, G.N., Anderson, C.B., Berman, M.G., Cochran, B., de Vries, S., Flanders, J., Folke, C., Frumkin, H., Gross, J.J., Hartig, T., Khan, P.H., Kuo, M., Lawler, J.J., Levin, P.S., Lindahl, T., MeyerLindenberg, A., Mitchell, R., Ouyang, Z., Roe, J., Scarlett, L., Smith, J.R., van den Bosch, M., Wheeler, B.W., White, M.P., Zheng, H. \& Daily, G.C. (2019) Nature and mental health: an ecosystem service perspective. Science Advances, 5, eaax0903.
Cardoso, P., Rigal, F. \& Carvalho, J.C. (2015) BAT - Biodiversity Assessment Tools, an R package for the measurement and estimation of alpha and beta taxon, phylogenetic and functional diversity. Methods in Ecology and Evolution, 6, 232-236.

Chao, A. (1984) Nonparametric estimation of the number of classes in a population. Scandinavian Journal of Statistics, 11, 265-270.

Dearborn, D.C. \& Kark, S. (2010) Motivaciones para conservar la biodiversidad urbana. Conservation Biology, 24, 432-440.

Devillers, P., Lafontaine, R.-M., Pasau, B., Daims, V., de Boeck, B., Boeckx, A., Boon, L. \& Devillers-Terschuren, J. (2019) La friche Josaphat à Bruxelles, Schaerbeek. Un site urbain enclavé d'une richesse odonatologique exceptionnelle. Les Naturalistes belges, 100, 1-22.

Dorchin, A., Dafni, A., Izhaki, I., Sapir, Y. \& Vereecken, N.J. (2018) Patterns and drivers of wild bee community assembly in a Mediterranean IUCN important plant area. Biodiversity and Conservation, 27, 695-717.

Dötterl, S. \& Vereecken, N.J. (2010) The chemical ecology and evolution of bee-flower interactions: a review and perspectives. Canadian Journal of Zoology, 88, 668-697.

Drossart, M., Rasmont, P., Vanormelingen, P., Dufrêne, M., Folschweiller, M., Pauly, A., Vereecken, N.J., Vray, S., Zambra, E., D'Haeseleer, J. \& Michez, D. (2019) Belgian Red List of bees. Belgian Science Policy 2018 (BRAIN-be - Belgian Research Action through Interdisciplinary Networks), pp. p. 140. Presse universitaire de l'Université de Mons, Mons.

Else, G. \& Edwards, M. (2018) Handbook of the Bees of the British Isles. Ray Society Monographs, Vol. 180. London, United Kingdom: Ray Society.

Falk, S.J. (2015) Field guide to the bees of Great Britain and Ireland. London, United Kingdom: British Wildlife Publishing.

Fischer, L.K., Eichfeld, J., Kowarik, I. \& Buchholz, S. (2016) Disentangling urban habitat and matrix effects on wild bee species. PeerJ, 11, e2729.

Fitch, G., Wilson, C.J., Glaum, P., Vaidya, C., Simao, M.C. \& Jamieson, M.A. (2019) Does urbanization favour exotic bee species? Implications for the conservation of native bees in cities. Biology Letters, 15, 20190574.

Goddard, M.A., Dougill, A.J. \& Benton, T.G. (2010) Scaling up from gardens: biodiversity conservation in urban environments. Trends in Ecology and Evolution, 25, 90-98.

Godefroid, S., Monbaliu, D. \& Koedam, N. (2007) The role of soil and microclimatic variables in the distribution patterns of urban wasteland flora in Brussels, Belgium. Landscape and Urban Planning, 80, $45-55$.

Gotelli, N.J. \& Colwell, R.K. (2001) Quantifying biodiversity: procedures and pitfalls in the measurement and comparison of species richness. Ecology Letters, 4, 379-391.

Gotelli, N.J. \& Cabe, D.J. (2002) Species co-occurrence: a meta-analysis on assembly rules model. Ecology, 83, 2091-2096.

Hill, B. \& Bartomeus, I. (2016) The potential of electricity transmission corridors in forested areas as bumblebee habitat. Royal Society Open Science, 3, 160525.

Jacobs, I., Jacobs, M. \& Lambrechts, J. (2019) Monitoring in het domein Most-Keiheuvel in Balen in het kader van het LIFE+ project natuurherstel Most-Keiheuvel. Natuurpunt Studie en Nature ID in opdracht van het Agentschap voor Natuur en Bos. Rapport Natuurpunt Studie 2019/2, Mechelen.

Kekenbosch, R. (2010) L'aranéofaune de la Région de Bruxelles-Capitale.Première partie: le site de l'ancienne gare de marchandise Josaphat à Schaerbeek. Feuille de contact la Société Arachnologique de Belgique, 25, 199-209.

Kembel, S.W., Cowan, P.D., Helmus, M.R., Cornwell, W.K., Morlon, H., Ackerly, D.D., Blomberg, S.P. \& Webb, C.O. (2010) 
Picante: R tools for integrating phylogenies and ecology. Bioinformatics, 26, 1463-1464.

Kowarik, I. (2011) Novel urban ecosystems, biodiversity, and conservation. Environmental Pollution, 159, 1974-1983.

Kühn, I. \& Klotz, S. (2006) Urbanization and homogenization - Comparing the floras of urban and rural areas in Germany. Biological Conservation, 127, 292-300.

Laliberte, E. \& Legendre, P. (2010) A distance-based framework for measuring functional diversity from multiple traits. Ecology, 91, 299-305.

Laliberté, E., Legendre, P. \& Shipley, B. (2014) FD: measuring functional diversity from multiple traits, and other tools for functional ecology. R package version 1.0-12.

Lambrechts, J., Jacobs, I. \& Jacobs, M. (2015) Monitoring in het domein Most-Keiheuvel in Balen in het kader van het LIFE+ project natuurherstel Most-Keiheuvel. Natuurpunt Studie en Nature ID in opdracht van het Agentschap voor Natuur en Bos. Rapport Natuurpunt Studie 2015/1, Mechelen (Belgium), 290 pp.

Lepczyk, C.A., Aronson, M.F.J., Evans, K.L., Goddard, M.A., Lerman, S.B. \& Macivor, J.S. (2017) Biodiversity in the city: fundamental questions for understanding the ecology of urban green spaces for biodiversity conservation. BioScience, 67, 799-807.

Mcdonald, R.I., Kareiva, P. \& Forman, R.T.T. (2008) The implications of current and future urbanization for global protected areas and biodiversity conservation. Biological Conservation, 141, 1695-1703.

Michez, D., Rasmot, P., Terzo, M. \& Vereecken, N.J. (2019) The Bees of Europe. NAP Editions, Paris, France.

Miller, J.R. \& Hobbs, R.J. (2002) Conservation where people live and work. Conservation Biology, 16, 330-337.

Mouillot, D., Graham, N.A.J., Villéger, S., Mason, N.W.H. \& Bellwood, D.R. (2013) A functional approach reveals community responses to disturbances. Trends in Ecology and Evolution, 28, 167-177.

Nieto, A., Roberts, S.P.M., Kemp, J., Rasmont, P., Kuhlmann, M., García Criado, M., Biesmeijer, J.C., Bogusch, P., Dathe, H.H., de la Rúa, P., de Meulemeester, T., Dehon, M., Dewulf, A., OrtizSánchez, F.J., Lhomme, P., Pauly, A., Potts, S.G., Praz, C., Quaranta, M., Radchenko, V.G., Scheuchl, E., Smit, J., Straka, J., Terzo, M., Tomozii, B., Window, J. \& Michez, D. (2014) European Red List of bees. Publication Office of the European Union, Luxembourg.

Normandin, É., Vereecken, N.J., Buddle, C.M. \& Fournier, V. (2017) Taxonomic and functional trait diversity of wild bees in different urban settings. PeerJ, 2017, e3051.

Observations.be. (2021) Bienvenue - Observations.be. <https:// observations.be/>

Oksanen, J., Blanchet, F.G., Friendly, M., Kindt, R., Legendre, P., Mcglinn, D., Blanchet, F.G., Minchin, P.R., O'hara, R.B., Simpson, G.L., Solymos, P., Henry, M., Stevens, H., Szoecs, E. \& Maintainer, H.W. (2020) vegan: community Ecology. Package. R package version 2.5-7. <https://CRAN.R-project.org/package= vegan>

Paradis, E. \& Schliep, K. (2019) Ape 5.0: An environment for modern phylogenetics and evolutionary analyses in R. Bioinformatics, 35, 526-528.

Pauly, A. (2019) Abeilles de Belgique et des Régions limitrophes (Insecta: Hymenoptera: Apoidea) Famille Halictidae. Faune de Belgique. Brussels, Belgium: Institut Royal des Sciences Naturelles de Belgique (IRScNB).

Pfefferbaum, B. \& North, C.S. (2020) Mental health and the Covid-19 pandemic. New England Journal of Medicine, 383, 510-512.
R Development Core Team (2020) R: A Language and Environment for Statistical Computing. R Foundation for Statistical Computing, Vienna, Austria.

Rasmussen, C., Engel, M.S. \& Vereecken, N.J. (2020) A primer of hostplant specialization in bees. Emerging Topics in Life Sciences, 4, 7-17.

RStudio Team (2020) RStudio: Integrated Development for R. RStudio, PBC, Boston, MA. http://www.rstudio.com/.

Rupprecht, C.D.D. \& Byrne, J.A. (2014) Informal urban greenspace: a typology and trilingual systematic review of its role for urban residents and trends in the literature. Urban Forestry and Urban Greening, 13, 597-611.

Rupprecht, C.D.D., Byrne, J.A., Ueda, H. \& Lo, A.Y. (2015) “It's real, not fake like a park": residents' perception and use of informal urban green-space in Brisbane, Australia and Sapporo, Japan. Landscape and Urban Planning, 143, 205-218.

Saintenoy-Simon, J. (1984) Compte rendu de l'excursion du 6 octobre 1984 dans la gare de Schaerbeek-Josaphat et dans l'avant-port de Bruxelles. Les Naturalistes belges, 65, 201-206.

Saintenoy-Simon, J. (2003) La gare Josaphat: vingt ans d'observations. Adoxa, 40-41, 1-6.

Saintenoy-Simon, J. (2012) Gare Josaphat: le printemps silencieux. Adoxa, 71, 45-48.

Saintenoy-Simon, J. (2018) Aperçu de la flore des friches de la Région de Bruxelles-Capitale. Les Naturalistes belges, 99, 1-31.

Saintenoy-Simon, J. (2019) Le site Josaphat jadis: le temps des mirabelles. Les Naturalistes belges, 100, 1-6.

Schadek, U., Strauss, B., Biedermann, R. \& Kleyer, M. (2008) Plant species richness, vegetation structure and soil resources of urban brownfield sites linked to successional age. Urban Ecosystems, 12, 115-126.

Schmid-Egger, C. \& Scheuchl, E. (1997) Illustrierte Bestimmungstabellen der Wildbienen Deutschlands und Österreichs unter Berücksichtigung der Arten der Schweiz. Band III: Andrenidae, Eigenverlag, Velden.

Shwartz, A., Turbé, A., Julliard, R., Simon, L. \& Prévot, A.C. (2014) Outstanding challenges for urban conservation research and action. Global Environmental Change, 28, 39-49.

Silva, J.L.d.S.e., Oliveira, M.T.P.d., Oliveira, W., Borges, L.A., CruzNeto, O. \& Lopes, A.V. (2020) High richness of exotic trees in tropical urban green spaces: reproductive systems, fruiting and associated risks to native species. Urban Forestry and Urban Greening, 50, 126659.

Small, E.C., Sadler, J.P. \& Telfer, M.G. (2002) Carabid beetle assemblages on urban derelict sites in Birmingham, UK. Journal of Insect Conservation, 6, 233-246.

Steinert, M., Sydenham, M.A.K., Eldegard, K. \& Moe, S.R. (2020) Conservation of solitary bees in power-line clearings: Sustained increase in habitat quality through woody debris removal. Global Ecology and Conservation, 21, e00823.

Strauss, B. \& Biedermann, R. (2006) Urban brownfields as temporary habitats: driving forces for the diversity of phytophagous insects. Ecography, 29, 928-940.

Taggar, A.K., Mcgrath, E. \& Despland, E. (2021) Competition between a native and introduced pollinator in unmanaged urban meadows. Biological Invasions, 23, 1697-1705.

Turo, K.J., Spring, M.L.R., Sivakoff, F.S., Delgado de la flor, Y.A. \& Gardiner, M.M. (2021) Conservation in post-industrial cities: how does vacant land management and landscape configuration influence urban bees? Journal of Applied Ecology, 58, 58-69.

Twerd, L. \& Banaszak-Cibicka, W. (2019) Wastelands: their attractiveness and importance for preserving the diversity of wild bees in urban areas. Journal of Insect Conservation, 23, 573-588.

United Nations. (2015). Take Action for the Sustainable Development Goals - United Nations Sustainable Development. https://www.un. 
org/sustainabledevelopment/sustainable-development-goals/. Accessed on February 20, 2021.

Vakhlamova, T., Rusterholz, H.-P., Kanibolotskaya, Y. \& Baur, B. (2014) Changes in plant diversity along an urban-rural gradient in an expanding city in Kazakhstan, Western Siberia. Landscape and Urban Planning, 132, 111-120.

Vereecken, N.J., Weekers, T., Leclercq, N., De Greef, S., Hainaut, H., Molenberg, J.-M., Martin, Y., Janssens, X., Noël, G., Pauly, A., Roberts, S.P.M. \& Marshall, L. (2021) Insect biomass is not a consistent proxy for biodiversity metrics in wild bees. Ecological Indicators, 121, 107132.

Villaseñor, N.R., Chiang, L.A., Hernández, H.J. \& Escobar, M.A.H. (2020) Vacant lands as refuges for native birds: an opportunity for biodiversity conservation in cities. Urban Forestry and Urban Greening, 49, 126632.

Vimal, R., Geniaux, G., Pluvinet, P., Napoleone, C. \& Lepart, J. (2012) Detecting threatened biodiversity by urbanization at regional and local scales using an urban sprawl simulation approach: application on the French Mediterranean region. Landscape and Urban Planning, 104, 343-355.

Wagner, D.L., Ascher, J.S. \& Bricker, N.K. (2014) A transmission rightof-way as habitat for wild bees (Hymenoptera: Apoidea: Anthophila) in Connecticut. Annals of the Entomological Society of America, 107, 1110-1120.

Webb, C.O., Ackerly, D.D., McPeek, M.A. \& Donoghue, M.J. (2002) Phylogenies and community ecology. Annual Review of Ecology and Systematics, 33, 475-505.
Westphal, C., Bommarco, R., Carré, G., Lamborn, E., Morison, N., Petanidou, T., Potts, S.G., Roberts, S.P.M., Szentgyörgyi, H., Tscheulin, T., Vaissière, B.E., Woyciechowski, M., Biesmeijer, J.C., Kunin, W.E., Settele, J. \& Steffan-Dewenter, I. (2008) Measuring bee diversity in different European habitats and biogeographical regions. Ecological Monographs, 78, 653-671.

Wilson, C.J. \& Jamieson, M.A. (2019) The effects of urbanization on bee communities depends on floral resource availability and bee functional traits. PLOS ONE, 14, e0225852.

Wojcik, V.A. \& Buchmann, S. (2012) A review of pollinator conservation and management on infrastructure supporting rights-of-way. Journal of Pollination Ecology, 7, 16-26.

Xie, J., Luo, S., Furuya, K. \& Sun, D. (2020) Urban parks as green buffers during the COVID-19 pandemic. Sustainability (Switzerland), 12, 6751.

$\mathrm{Yu}$, G. (2020) Using ggtree to visualize data on tree-like structures. Current Protocols in Bioinformatics, 69, e96.

Yu, G., Smith, D.K., Zhu, H., Guan, Y. \& Lam, T.T.Y. (2017) Ggtree: an $\mathrm{R}$ package for visualization and annotation of phylogenetic trees with their covariates and other associated data. Methods in Ecology and Evolution, 8, 28-36.

Zorenko, T. (2003) Species diversity and distribution of mammals in Riga. Acta Zoologica Lituanica, 13, 78-86.

Accepted 4 June 2021

Editor: Laurence Packer; Associate Editor: Robert Minckley 